\title{
Neuroprotective effects of astragaloside IV on Parkinson disease models of mice and primary astrocytes
}

\author{
LEI XIA ${ }^{1}$, DIANXUAN GUO ${ }^{2}$ and BING $\mathrm{CHEN}^{1}$ \\ ${ }^{1}$ Department of Neurology, Huai'an First People's Hospital, Nanjing Medical University, Huai'an, Jiangsu 223300; \\ ${ }^{2}$ Department of Geriatrics, The Affiliated Huai'an Hospital of Xuzhou Medical University, \\ Huai'an, Jiangsu 223002, P.R. China
}

Received February 14, 2017; Accepted September 15, 2017

DOI: $10.3892 / \mathrm{etm} .2017 .5238$

\begin{abstract}
Parkinson's disease (PD) is characterized by a progressive degeneration of dopaminergic neurons in the substantia nigra pars compacta. Inflammation and neural degeneration are implicated in the pathogenesis of PD. Astragaloside IV (AS-IV) has been verified to attenuate inflammation. The current study aimed to investigate the role of AS-IV in PD and the possible molecular mechanisms. Pole, traction and swim tests were performed to examine the effects of AS-IV on 1-methyl-4-phenyl-1, 2, 3, 6-tetrahydropyridine (MPTP)-generated behavioral deficiencies in vivo. Meanwhile, as for in vitro experiments, the influence of AS-IV on cell viability was evaluated using the 3-(4,5-dimethyl-2-thiazolyl)-2, 5-diphenyl-2-H-tetrazolium bromide (MTT) assay, the effects of AS-IV on 1-methyl-4-phenylpyridnium ion (MPP+)-induced cell viability changes were tested using MTT assays, cell apoptosis rates were assessed using an Annexin-V Fluorescein isothiocyanate kit, and the expression levels of phosphorylated-Jun N-terminal kinase (p-JNK), Bcl-2-associated $\mathrm{X}$ protein $(\mathrm{Bax}) / \mathrm{Bcl}-2$ and caspase- 3 activity were assessed using western blot analysis. Behavioral tests showed that pretreatment of AS-IV significantly alleviated MPTP-generated behavioral deficiencies in vivo. Meanwhile, AS-IV remarkably rescued MPP+-induced cell viability reduction, increase in cell apoptosis rate, and upregulation of $\mathrm{p}-\mathrm{JNK}, \mathrm{Bax} / \mathrm{Bcl}-2$ ratio and caspase-3 activity in vitro. In conclusion, AS-IV may be a promising neuroprotective agent for PD.
\end{abstract}

\section{Introduction}

PD, the second most common neurodegenerative disorder after Alzheimer's disease (AD), is tightly associated with

Correspondence to: Mrs Bing Chen, Department of Neurology, Huai'an First People's Hospital, Nanjing Medical University, 6 Beijing Road West, Huai'an, Jiangsu 223300, P.R. China

E-mail: chenbinghah@163.com

Key words: Parkinson's disease, astragaloside IV, astrocytes aging, the morbidity of which is approximate $2 \%$ in the older. PD impacts basal ganglia in patients who typically experience bradykinesia, rigidity, tremor and disturbed balance (1). The precise mechanisms of PD remain elusive, previous studies suggested mitochondrial dysfunction (2), neuro-inflammation (3) as well as oxidative stress (4) were involved in this process. Neurological degeneration can be deteriorated by chronic inflammation in the central nervous system (CNS) which involves recruitment of cytotoxic molecules, free radicals and glutamate that have the potential to provoke neuritic beading, excitotoxic, apoptotic and necrotic degeneration (5).

In China, astragalus membranaceus was utilized for patients with chronic diseases and healthy individuals who wish to further improve vital functions (6). AS-IV, the primary pure saponin which is isolated from the root of astragalus membranaceus, was an effective compound with distinct pharmacological effects, including protecting against ischemic brain injury (6), lung inflammation (7), acute pancreatitis (8) and cardiac trauma (9).

Astrocyte dysfunction and even astrocyte dysregulation critically affected neuronal survival (10). Traditionally, necrosis was deemed to be the predominant mechanism of astrocyte death in brain injury models, moreover, mounting evidences demonstrated that astrocytic apoptosis might contribute to the pathogenesis of multiple neurodegenerative disorders, for instance, AD and PD $(11,12)$.

In 1947, MPTP was first synthesized by Lee et al as an analgesic (13). It caused Parkinsonism in primates including humans, rodents (less susceptible) and rats (almost immune). After MPTP administration, mice were reported to only suffer from cell death in SNPC (14), excitingly, most of the recent studies indicated the appearance of Parkinsonism-like syndromes (especially chronically) as well (15).

$\mathrm{MPP}+$, whose prodrug is MPTP, is a neurotoxin which selectively destroy nigral DA neurons and is also widely used to establish PD experimental models in vitro $(16,17)$. MPP+ has been shown to induce a syndrome closely resembling PD in cellular and animal models $(18,19)$.

To the best of our knowledge, as yet, whether and how AS-IV displays protective effects on MPTP generated PD in mice and MPP+ induced PD in astrocytes remain elusive. Our data suggested that AS-IV may be a promising agent for the prevention and therapy of PD. 


\section{Materials and methods}

Animals. Adult male C57BL/6 mice aged 8 weeks were used in current study. Mice were randomly divided into 6 different groups: i) ethanol-propylene glycol $(10 \mu 1)+$ negative control (NC) group; ii) ethanol-propylene glycol $(10 \mu \mathrm{l})+$ MPTP group; iii) AS-IV $(1.5 \mathrm{mg} / \mathrm{kg} / 10 \mu \mathrm{l})+$ MPTP group; iv) AS-IV (3 mg/kg/10 $\mu \mathrm{l})+$ MPTP group; v) AS-IV $(6 \mathrm{mg} / \mathrm{kg} / 10 \mu \mathrm{l})+$ MPTP group and vi) AS-IV $(6 \mathrm{mg} / \mathrm{kg} / 10 \mu \mathrm{l})$ group, with 10 mice in each group. Mice were housed in a temperature-controlled room with a 12 -hour light/dark cycle and were free to food/water.

PD model was obtained by MPTP (30 mg/kg/10 $\mu 1$, i.p.) injection for consecutive 5 days. As for AS-IV, it was dissolved in ethanol-propylene glycol (50:50 v/v), and injected once a day 30 min before MPTP injection. Eight hours after MPTP administration, behavioral tests were carried out at 1 day before MPTP injection, and at 1th/4th/7th/10th day after MPTP injection, respectively. Mice were handled according to the National Institutes of Health (NIH, Bethesda, MD) Guide for the Care and Use of Laboratory Animals (NIH publication 80-23, revised 1996). Experiments were approved by the Institutional Animal Care and Use Committee (IACUC) of Nanjing Medical University.

Pole test. A ball with the diameter of $2.5 \mathrm{~cm}$ was fixed at the top of the wooden pole which was at the length of $50 \mathrm{~cm}$ and at the thickness of $1 \mathrm{~cm}$. Mice were placed on the ball to evaluate the different time spending on getting down from the ball. Results were re-tested when mice climbed to the reverse direction or stopped. Each mice was tested for 2-3 times one day. We carried out this test in accordance to a previous reported study (20).

Traction test. Mice were suspended on a horizontal with a distance of $30 \mathrm{~cm}$ to a platform for observing their hang time. Criteria were as followed: 0-4 sec recorded as 0 score, $5-9 \mathrm{sec}$ recorded as 1 score, $10-14 \mathrm{sec}$ recorded as $2 \mathrm{score}, 15-19 \mathrm{sec}$ recorded as 3 score, 20-24 sec recorded as 4 score, $25-29 \mathrm{sec}$ recorded as 5 score, $>30 \mathrm{sec}$ recorded as 6 score. They were recorded as previously performed (21).

Swim test. Mice were placed in a $20 \times 30 \times 20 \mathrm{~cm}$ pool with the temperature of $28-30^{\circ} \mathrm{C}$, swim situation within $1 \mathrm{~min}$ was recorded. Criteria were as followed: 3.0, swims successively; 2.5 , swims for the most time; 2.0 , floating time is longer than $30 \mathrm{sec}$; 1.5 ; swims occasionally; 1 , swims occasionally and floating for almost all the time. This test was carried out as previously described (22).

Cell culture. Primary astrocytes were derived from 1-5 day postnatal mice. In brief, the cerebral cortices were minced in the medium which contained $20 \mu \mathrm{g} / \mathrm{ml}$ DNase and $0.3 \%$ bovine serum albumin (BSA).

Tissues were digested in $0.25 \%$ trypsin solution at $37^{\circ} \mathrm{C}$ for $30 \mathrm{~min}$. The suspension was filtered through 70 um nylon filter, pelleted by centrifugation to remove trypsin. Afterwards, pellets were re-suspended in $10 \%$ (v/v) fetal bovine serum (FBS) and $1 \%$ penicillin $/ 1 \%$ streptomycin containing Dulbecco's modified Eagle's medium/F12 (DMEM/F12), followed by transferation to flasks and incubation under the conditions of $37^{\circ} \mathrm{C}, 5 \% \mathrm{CO}_{2}$ and $90 \%$ relative humidity. When cells reached confluence, flasks were gently shaken to remove microglia cells and oligodendrocytes. Astrocytes were rinsed with phosphate buffered saline (PBS) for three times. Thereafter, astrocytes were trypsinized and loosened by patting the flasks, thereafter, they were placed in a new flasks and cultured in DMEM/F12 (15\% FBS, L-glutamine and $500 \mathrm{ng} / \mathrm{ml}$ insulin) until confluent.

$\mathrm{MPP}+(4 \mathrm{mM} / \mathrm{l})$ was used in primary astrocyte to obtain cellular model of PD. Different concentrations of AS-IV (10, 20 and $40 \mu \mathrm{M} / \mathrm{l})$ were administrated $2 \mathrm{~h}$ prior to MPP+, at $24 \mathrm{~h}$ following MPP+ treatment, astrocytes were used for following experiments.

MTT assay. Cell viability was measured by MTT assay. Approximately $200 \mu \mathrm{l}$ cells at the concentration of $1 \times 10^{4} / \mathrm{ml}$ were seeded into 96-well plates. After incubation of cells for $24 \mathrm{~h}, 20 \mu \mathrm{l}$ of $5 \mathrm{mg} / \mathrm{ml}$ MTT solution was added to each well and the plate was further incubated at $37^{\circ} \mathrm{C}$ for another $4 \mathrm{~h}$. Afterwards, wells were rinsed with PBS for 3 times, and $150 \mu \mathrm{l}$ DMSO was added into each well. The microtitre plate was placed on a shaker to dissolve the dye thoroughly. Absorbance at $450 \mathrm{~nm}$ was read using a Bio-Rad iMark plate reader.

Annexin-V Fluorescein (FITC). Astrocytic apoptosis was assessed by FITC apoptosis detection kit (Oncogene Research Products, San Diego, CA, USA) according to manufacturer's instructions. Cell samples were analyzed by flow cytometry apparatus (Becton Dickinson FACSVantage SE, San Jose, CA, USA). Dual analysis was adopted in the present study, necrotic cells were propidium iodide (PI)-positive, early apoptotic cells were Annexin V-FITC-positive, while cells at the state of late apoptosis were double-positive for Annexin V-FITC and PI. Cells that were stained with neither Annexin V-FITC nor PI were classified as live cells.

Western blotting. Expression levels of glyceraldehyde 3-phosphate dehydrogenase (GAPDH), p-JNK, caspase-3 and $\mathrm{Bax} / \mathrm{Bcl}-2$ were evaluated by western blot. Briefly, astrocyte extract lysates were washed with pre-cold PBS and homogenized in RIPA lysis buffer which contained a cocktail of protease inhibitors and phosphatase inhibitors (Roche Diagnostics, Shanghai, China). Samples were separated by sodium dodecyl sulfate polyacrylamide gel electrophoresis (SDS-PAGE) and electro-transferred onto polyvinylidene fluoride (PVDF) membranes (Millipore, Bedford, USA). Afterwards, PVDM membranes were blocked in 5\% bull serum albumin (BSA) for $1 \mathrm{~h}$ at room temperature, and incubated overnight at $4^{\circ} \mathrm{C}$ with the corresponding primary antibodies. After washing with Tris-Buffered Saline and Tween-20 (TBST), PVDF membranes were incubated with horse radish peroxidase (HRP)-conjugated secondary antibody for $1 \mathrm{~h}$ at room temperature. GAPDH performed as a loading control.

Statistical analysis. Differences among groups were tested with two-way ANOVA. Data were presented as mean \pm standard deviation (SD). Significance is determined on a criterion of $\mathrm{P}<0.05$. 
Table I. AS-IV pretreatment attenuates MPTP-induced deficiency in ability of moving.

\begin{tabular}{|c|c|c|c|c|c|}
\hline Time point & $\begin{array}{c}\text { Ethanol-propylene } \\
\text { glycol + NC }\end{array}$ & $\begin{array}{l}\text { Ethanol-propylene } \\
\text { glycol + MPTP }\end{array}$ & $\begin{array}{l}\text { AS-IV } 1.5 \mathrm{mg} / \mathrm{kg} \\
\pm \mathrm{MPTP}\end{array}$ & $\begin{array}{c}\text { AS-IV3.0 mg/kg } \\
\pm \mathrm{MPTP}\end{array}$ & $\begin{array}{l}\text { AS-IV } 6 \mathrm{mg} / \mathrm{kg} \\
\quad \pm \text { MPTP }\end{array}$ \\
\hline 1 day before PD (Score) & $5.53 \pm 0.91$ & $5.52 \pm 1.50$ & $5.03 \pm 1.32$ & $5.10 \pm 1.30$ & $5.35 \pm 1.24$ \\
\hline 1st day after PD (Score) & $5.48 \pm 0.86$ & $5.78 \pm 1.53$ & $5.27 \pm 1.55$ & $6.17 \pm 1.43$ & $5.77 \pm 1.35$ \\
\hline 4th day after PD (Score) & $5.61 \pm 0.73$ & $7.94 \pm 1.87^{\mathrm{a}}$ & $7.52 \pm 1.83^{\mathrm{b}}$ & $7.22 \pm 1.69^{b}$ & $7.07 \pm 1.23^{\mathrm{c}}$ \\
\hline 7th day after PD (Score) & $5.36 \pm 0.81$ & $7.31 \pm 1.36^{\mathrm{a}}$ & $7.15 \pm 1.38^{b}$ & $6.99 \pm 1.32^{\mathrm{b}}$ & $6.81 \pm 1.34^{c}$ \\
\hline 10th day after PD (Score) & $5.68 \pm 0.98$ & $7.13 \pm 1.45^{\mathrm{a}}$ & $6.83 \pm 1.48^{b}$ & $6.66 \pm 1.54^{\mathrm{b}}$ & $6.55 \pm 1.41^{\mathrm{c}}$ \\
\hline
\end{tabular}

${ }^{\mathrm{a}} \mathrm{P}<0.01$ MPTP group vs. NC group; ${ }^{\mathrm{b}} \mathrm{P}<0.05$; and ${ }^{\mathrm{c}} \mathrm{P}<0.01$, AS-IV group vs. MPTP group. MPTP, 1-methyl-4-phenyl-1,2,3,6-tetrahydropyridine; $\mathrm{NC}$, negative control; AS-IV, astragaloside-IV; PD, Parkinson's disease.

Table II. AS-IV pretreatment ameliorates MPTP-induced suspension deficiency.

\begin{tabular}{|c|c|c|c|c|c|}
\hline Time point & $\begin{array}{c}\text { Ethanol-propylene } \\
\text { glycol + NC }\end{array}$ & $\begin{array}{c}\text { Ethanol-propylene } \\
\text { glycol + MPTP }\end{array}$ & $\begin{array}{c}\text { AS-IV } 1.5 \mathrm{mg} / \mathrm{kg} \\
\pm \text { MPTP }\end{array}$ & $\begin{array}{c}\text { AS-IV3.0 mg/kg } \\
\pm \text { MPTP }\end{array}$ & $\begin{array}{c}\text { AS-IV6 mg/kg } \\
\pm \text { MPTP }\end{array}$ \\
\hline 1 day before PD (Score) & $2.83 \pm 0.41$ & $2.83 \pm 0.65$ & $2.83 \pm 0.52$ & $2.85 \pm 0.56$ & $2.86 \pm 0.64$ \\
\hline 1st day after PD (Score) & $3.00 \pm 0.36$ & $3.02 \pm 0.86^{\mathrm{a}}$ & $2.93 \pm 0.55^{\mathrm{b}}$ & $2.91 \pm 0.63^{b}$ & $2.96 \pm 0.75^{\mathrm{c}}$ \\
\hline 4th day after PD (Score) & $2.90 \pm 0.46$ & $2.20 \pm 0.83^{\mathrm{a}}$ & $2.40 \pm 0.83^{\mathrm{b}}$ & $2.60 \pm 0.69^{b}$ & $2.87 \pm 0.23^{c}$ \\
\hline 7th day after PD (Score) & $2.92 \pm 0.48$ & $2.00 \pm 0.39^{\mathrm{a}}$ & $2.30 \pm 0.36^{\mathrm{b}}$ & $2.42 \pm 0.32^{b}$ & $2.49 \pm 0.34^{c}$ \\
\hline 10th day after PD (Score) & $2.94 \pm 0.48$ & $2.41 \pm 0.53^{\mathrm{a}}$ & $2.50 \pm 0.45^{\mathrm{b}}$ & $2.63 \pm 0.54^{\mathrm{b}}$ & $2.74 \pm 0.41^{\mathrm{c}}$ \\
\hline
\end{tabular}

${ }^{a} \mathrm{P}<0.01$ MPTP group vs. NC group; ${ }^{\mathrm{b}} \mathrm{P}<0.05$; and ${ }^{\mathrm{c}} \mathrm{P}<0.01$ AS-IV group vs. MPTP group. NC, negative control; MPTP, 1-methyl-4-phenyl-1,2,3,6-tetrahydropyridine; AS-IV, astragaloside-IV; PD, Parkinson's disease.

Table III. AS-IV pretreatment ameliorates MPTP-induced swim deficiency.

\begin{tabular}{|c|c|c|c|c|c|}
\hline Time point & $\begin{array}{c}\text { Ethanol-propylene } \\
\text { glycol + NC }\end{array}$ & $\begin{array}{l}\text { Ethanol-propylene } \\
\text { glycol + MPTP }\end{array}$ & $\begin{array}{c}\text { AS-IV } 1.5 \mathrm{mg} / \mathrm{kg} \\
\pm \mathrm{MPTP}\end{array}$ & $\begin{array}{l}\text { AS-IV3.0 mg } / \mathrm{kg} \\
\pm \text { MPTP }\end{array}$ & $\begin{array}{c}\text { AS-IV6 mg/kg } \\
\pm \text { MPTP }\end{array}$ \\
\hline 1 day before PD (Score) & $3.04 \pm 0.11$ & $3.03 \pm 0.05$ & $3.03 \pm 0.07$ & $3.05 \pm 0.06$ & $3.06 \pm 0.04$ \\
\hline 1st day after PD (Score) & $3.20 \pm 0.16$ & $3.22 \pm 0.16^{\mathrm{a}}$ & $3.13 \pm 0.25^{\mathrm{b}}$ & $3.11 \pm 0.33^{\mathrm{b}}$ & $3.12 \pm 0.25^{\mathrm{c}}$ \\
\hline 4th day after PD (Score) & $3.10 \pm 0.06$ & $2.42 \pm 0.13^{\mathrm{a}}$ & $2.75 \pm 0.33^{\mathrm{b}}$ & $2.86 \pm 0.29^{b}$ & $2.89 \pm 0.23^{c}$ \\
\hline 7th day after PD (Score) & $3.12 \pm 0.08$ & $2.23 \pm 0.09^{\mathrm{a}}$ & $2.43 \pm 0.31^{\mathrm{b}}$ & $2.54 \pm 0.30^{\mathrm{b}}$ & $2.59 \pm 0.20^{c}$ \\
\hline 10th day after PD (Score) & $3.14 \pm 0.12$ & $2.35 \pm 0.12^{\mathrm{a}}$ & $2.77 \pm 0.35^{\mathrm{b}}$ & $2.73 \pm 0.24^{\mathrm{b}}$ & $2.83 \pm 0.21^{\mathrm{c}}$ \\
\hline
\end{tabular}

aP $<0.01$ MPTPgroup vs. NC group, ${ }^{\text {b }} \mathrm{P}<0.05,{ }^{\mathrm{c}} \mathrm{P}<0.01 \mathrm{AS}-\mathrm{IV}$ group vs. MPTP group. NC, negative control; MPTP, 1-methyl-4-phenyl-1,2,3,6-tetrahydropyridine; AS-IV, astragaloside-IV; PD, Parkinson's disease.

\section{Results}

Pole test manifests that pretreatment of AS-IV attenuates MPTP-induced moving deficiency. MPTP was utilized for the establishment of PD model in vivo. There was no significant difference in climbing time between MPTP group and NC group at one day before/after modeling. However, from 4th-10th day after MPTP injection, mice displayed significantly longer time on climbing than that in NC group. Moreover, AS-IV pretreatment remarkably attenuated MPTP-induced extending of climbing time. Data were showed in Table I. Mice treated with AS-IV $(6 \mathrm{mg} / \mathrm{kg} / 10 \mu \mathrm{l})$ did not exhibit significant change in climbing time (data were not shown).

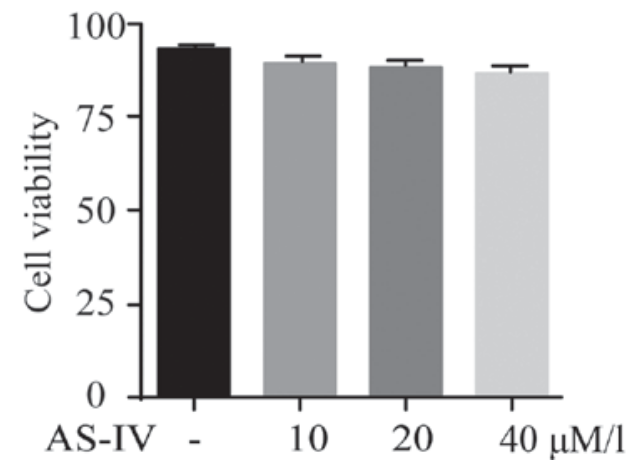

Figure 1. AS-IV shows no cytotoxicity on astrocytes. AS-IV alone did not affect the cell viability of astrocytes. AS-IV, astragaloside-IV. 
A

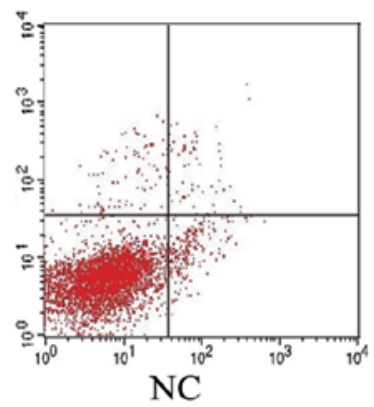

D

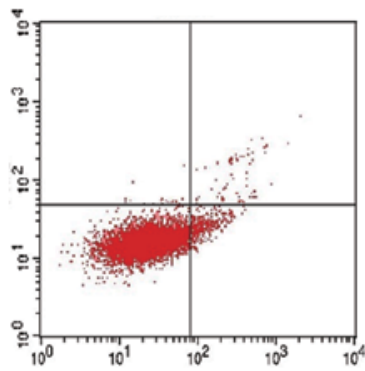

$\mathrm{MPP}++20 \mu \mathrm{m} / 1$ AS-IV
B

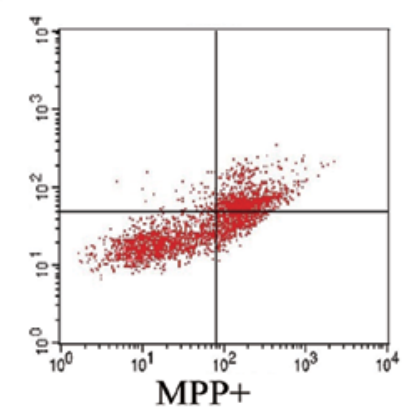

E

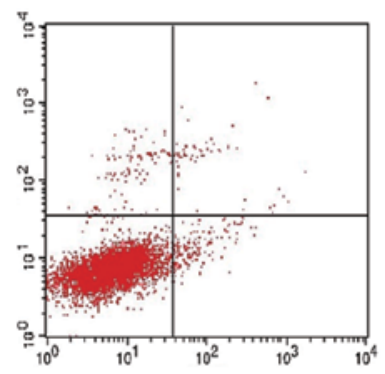

MPP $++40 \mu \mathrm{m} / 1$ AS-IV
C
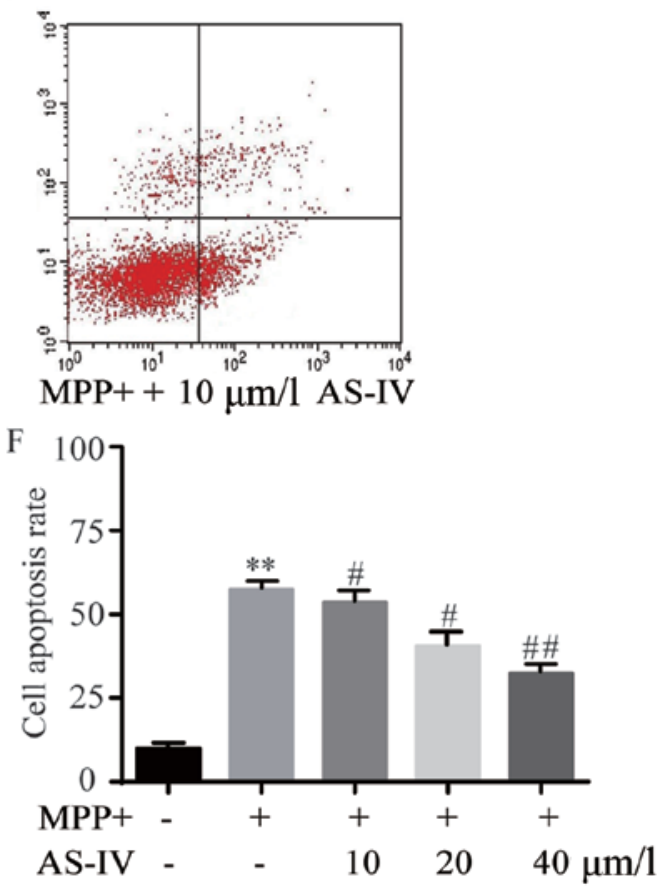

Figure 2. AS-IV attenuates MPP+-induced astrocyte cell apoptosis. In comparison with NC group, astrocytes that were administrated with MPP+ exhibited predominantly elevated cell apoptosis (A and B), which was significantly reversed by co-administration with AS-IV dose-dependently (C-E). Consistently, the corresponding statistical data of cell apoptosis rate were displayed (F). ${ }^{* *} \mathrm{P}<0.01 \mathrm{MPP}+$ group vs. NC group, ${ }^{\#} \mathrm{P}<0.05,{ }^{\# \#} \mathrm{P}<0.01 \mathrm{AS}-\mathrm{IV}$ groups vs. MPTP group, respectively. NC, negative control; AS-IV, astragaloside-IV; MPP+, 1-methyl-4-phenylpyridnium ion; MPTP, 1-methyl-4-phenyl-1, 2, 3, 6-tetrahydropyridine.

Traction test demonstrates that pretreatment of AS-IV ameliorates MPTP-induced suspension deficiency. No significant difference was found in suspension score between MPTP group and NC group at one day before/after modeling. Nevertheless, compared with NC group, mice in MPTP group displayed lower suspension score from 4th to 10th day after modelling which was remarkably reversed by AS-IV pretreatment. Data were displayed in Table II. Mice treated with AS-IV $(6 \mathrm{mg} / \mathrm{kg} / 10 \mu \mathrm{l})$ did not exhibit significant change in suspension score (data were not shown).

Swim test indicates that pretreatment of AS-IV ameliorates MPTP-induced swim deficiency. At one day before/after modeling, no significant difference was found in swim score between MPTP group and NC group. Whereas, from 4th-10th day after MPTP injection, mice exhibited lower swimming score in comparison with NC group. Moreover, AS-IV pretreatment remarkably reversed MPTP-induced swimming score downregulation. Data were exhibited in Table III. Mice treated with AS-IV $(6 \mathrm{mg} / \mathrm{kg} / 10 \mu \mathrm{l})$ did not exhibit significant change in swim score (data were not shown).

AS-IV shows no cytotoxicity on primary astrocytes. MPP+ was utilized for the establishment of PD model in vitro. Influence of AS-IV on cultured astrocytes was tested by MTT assay. Results revealed that AS-IV alone did not affect the cell viability of astrocytes as shown in Fig. 1.

AS-IV attenuates MPP+-induced cell apoptosis of astrocytes. In comparison with NC group, astrocytes administrated with

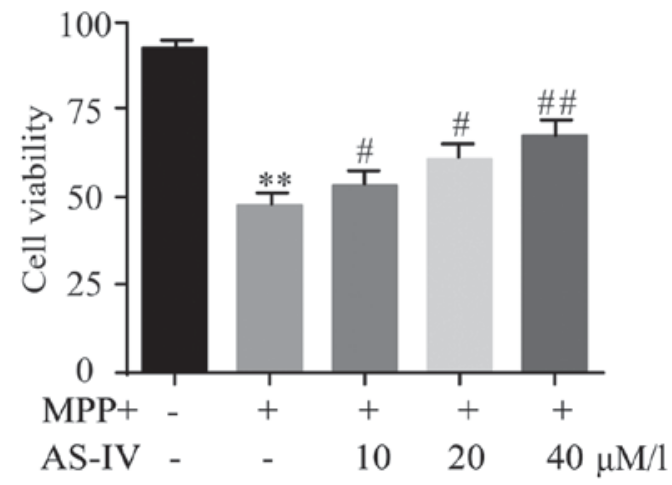

Figure 3. AS-IV rescues MPP+-induced astrocyte cell viability reduction. AS-IV significantly improved the downregulated astrocyte cell viability which was generated by $\mathrm{MPP}+{ }^{* *} \mathrm{P}<0.01 \mathrm{MPP}+$ group vs. NC group, ${ }^{\#} \mathrm{P}<0.05,{ }^{\# \#} \mathrm{P}<0.01$ AS-IV groups vs. MPTP group, respectively. NC, negative control; AS-IV, astragaloside-IV; MPP+, 1-methyl-4-phenylpyridnium ion; MPTP, 1-methyl-4-phenyl-1, 2, 3, 6-tetrahydropyridine.

MPP+ have exhibited predominantly elevated apoptotic cell number (Fig. 2A and B), which was significantly reversed by co-administration of AS-IV (Fig. 2C-E). Consistently, the corresponding statistical data of cell apoptosis rate were displayed as in Fig. 2F.

$A S-I V$ rescues $M P P+-i n d u c e d$ cell viability reduction of astrocytes. Influence of AS-IV on cell viability of cultured astrocytes was evaluated by MTT assay. Results revealed that AS-IV significantly improved the downregulated astrocyte cell viability which was generated by MPP+ (Fig. 3). 
A

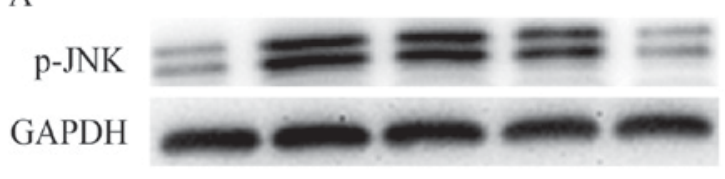

B

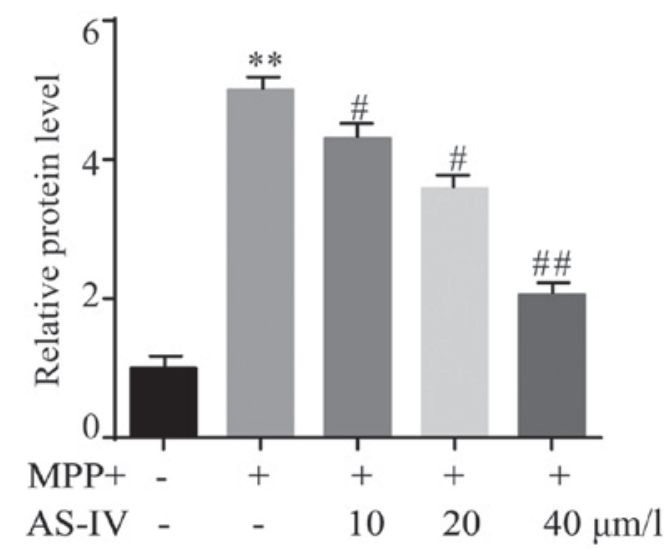

Figure 4. AS-IV reduces MPP+-induced elevation of p-JNK in astrocytes. AS-IV inhibited MPP+ induced over-expression of p-JNK in a dose-dependent manner (A). The statistical data verified that AS-IV notably repressed $\mathrm{MPP}+$ generated upregulation of $\mathrm{p}-\mathrm{JNK}(\mathrm{B})$. $^{* *} \mathrm{P}<0.01 \mathrm{MPP}+$ group vs. NC group, ${ }^{\#} \mathrm{P}<0.05,{ }^{\# \#} \mathrm{P}<0.01$ AS-IV group vs. MPTP group. NC, negative control; AS-IV, astragaloside-IV; MPP+, 1-methyl-4-phenylpyridnium ion; p-JNK, phosphorylated-Jun N-terminal kinase; GAPDH, glyceraldehyde 3-phosphate dehydrogenase; MPTP, 1-methyl-4-phenyl-1, 2, 3, 6-tetrahydropyridine.

$A S-I V$ reduces $M P P+-i n d u c e d$ elevation of $p$-JNK in astrocytes. The protein level of p-JNK in different groups was assessed by western blot. AS-IV pretreatment dose-dependently inhibited over-expression of p-JNK caused by MPP+ (Fig. 4A). The statistical data were presented and demonstrated that AS-IV notably repressed the upregulation of p-JNK that was induced by MPP+ (Fig. 4B).

$A S-I V$ represses $M P P+-i n d u c e d$ rise of $B a x / B c l-2$ ratio in astrocytes. In MPP+ group, Bax protein level was significantly higher than NC group, while Bcl-2 manifested an opposite change profile. Surprisingly, both MPP+-induced upregulation of Bax and downregulation of Bcl-2 were reversed by AS-IV (Fig. 5A). After MPP+ treatment, Bax/Bcl-2 ratio was obviously higher than NC group, which was remarkably attenuated by AS-IV as in Fig. 5B.

AS-IV attenuates MPP+-induced cleaved caspase-3 activation in astrocytes. MPP+ elevated the immunoreactivity of cleaved caspase-3 significantly. Astrocytes that were co-administrated with AS-IV $(20,40 \mu \mathrm{M} / 1)$ exhibited a significant lower caspase-3 activity than those treated with MPP+ (Fig. 6A). The statistical data were consistent with the result of western blot (Fig. 6B).

\section{Discussion}

We found that after injection of MPTP within $6 \mathrm{~h}$, mice in model group presented acute responses, including piloerection and fremitus. While at 4th-10th day after PD model establishment, mice exhibited dyskinesia (chronic responses), for
A

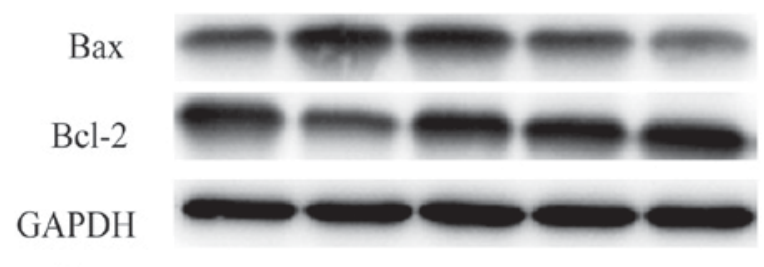

B

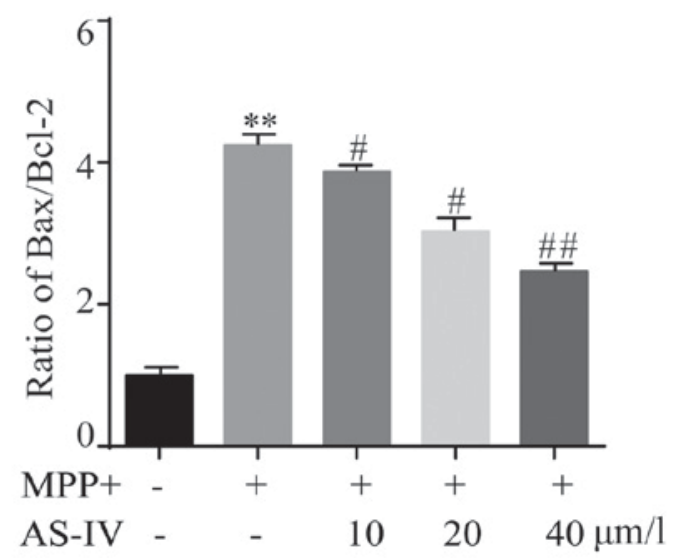

Figure 5. AS-IV represses MPP+-induced rise of Bax/Bcl-2 ratio in astrocytes In $\mathrm{MPP}+$ group, Bax protein level was significantly higher and Bcl-2 protein level was lower compared to NC group. MPP+-induced upregulation of Bax and downregulation of Bcl-2 were reversed by AS-IV (A). After MPP+ treatment, Bax/Bcl-2 ratio was obviously higher than that in NC group, which was remarkably attenuated by AS-IV (B). ${ }^{* *} \mathrm{P}<0.01 \mathrm{MPP}+$ group vs. NC group, ${ }^{\#} \mathrm{P}<0.05,{ }^{\# \#} \mathrm{P}<0.01$ AS-IV groups vs. MPTP group, respectively. NC, negative control; AS-IV, astragaloside-IV; MPP+, 1-methyl-4-phenylpyridnium ion; GAPDH, glyceraldehyde 3-phosphate dehydrogenase; Bax, Bcl-2-associated $\mathrm{X}$ protein; MPTP, 1-methyl-4-phenyl-1, 2, 3, 6-tetrahydropyridine.

\section{A}

\section{Caspase-3}

\section{GAPDH}

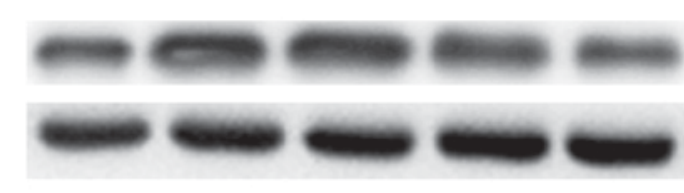

B

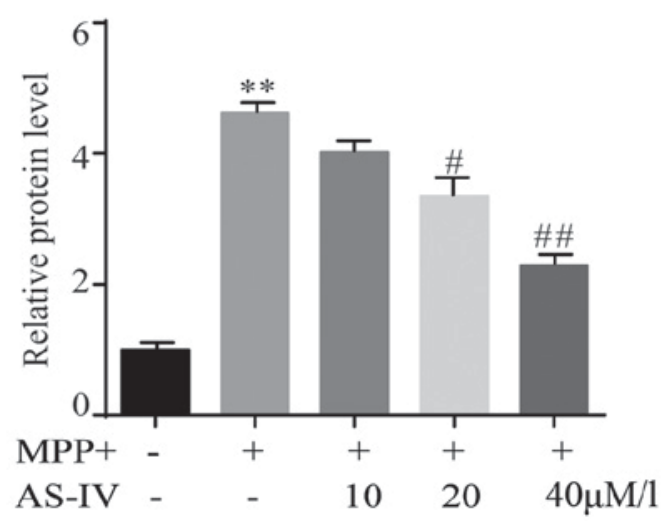

Figure 6. AS-IV attenuates MPP+-induced cleaved caspase-3 activation in astrocytes. MPP+ elevated the immunoreactivity of cleaved caspase-3 significantly in comparison with NC group. AS-IV (20, $40 \mathrm{uM} / 1)$ exhibited a significant lower caspase- 3 activity compared to MPP+ group (A). The corresponding statistical data were consistent with the result of western blot (B). ${ }^{* *} \mathrm{P}<0.01 \mathrm{MPP}+$ group vs. NC group, ${ }^{\#} \mathrm{P}<0.05,{ }^{\# \#} \mathrm{P}<0.01$ AS-IV group vs. MPTP group. NC, negative control; AS-IV, astragaloside-IV; MPP+ 1-methyl-4-phenylpyridnium ion; GAPDH, glyceraldehyde 3-phosphate dehydrogenase; MPTP, 1-methyl-4-phenyl-1, 2, 3, 6-tetrahydropyridine. 
instance, expansion of climbing time and decline of suspension/swimming time, which were consistent with previous reported studies (20-22). Taken together, these behavioral tests demonstrated the successful obtainment of PD model in vivo. And AS-IV dose-dependently attenuated the responses of PD mice, moreover, $6 \mathrm{mg} / \mathrm{kg}$ AS-IV significantly improved the aforementioned behavioral deficiencies. Mice injected with only $6 \mathrm{mg} / \mathrm{kg}$ AS-IV did not exhibit obvious behavioral changes, which suggested that protective effects of AS-IV on PD mice have been dependent on changes of intracellular signaling pathways.

We are eager to explore the effects of MPP+ on PD model in vitro. We first investigated whether AS-IV alone showed cytotoxicity on astrocytes. MTT assay was carried out and verified that AS-IV $(10,20$ and $40 \mu \mathrm{M})$ did not exhibit serious toxic effects in vitro. Thereafter, we performed the experiments as followed.

Effects of AS-IV on MPP+ induced astrocyte cell apoptosis was conducted by FITC. After the establishment of PD model in vitro, higher cell apoptosis rate was found in MPP+ group compared with NC group, which was dose-dependently and significantly rescued by co-administration of 20 or $40 \mu \mathrm{M} / 1$ AS-IV. These data suggested that AS-IV served as a protective role against MPP+-induced cytotoxicity in astrocytes.

Meanwhile, we evaluated the influence of AS-IV on cell viability of astrocytes. MTT assay indicated significantly lower cell viability in MPP+ group than that in NC group, and AS-IV (10, 20 and $40 \mu \mathrm{M} / 1)$ co-administration elevated MPP+ induced downregulation of cell viability a dose-dependent manner.

JNK signaling pathway was known to be implicated in numerous kinds of stress-mediated apoptosis, for instance, nerve growth factor withdrawal, excitotoxic stress and oxidative stress $(23,24)$. And elevation of p-JNK (activated JNK) was discovered in SNc of MPTP-treated PD mice $(25,26)$. Mounting evidences manifested the involvement of JNK in the process of cell apoptosis (27). We did western blot to assess protein level of $\mathrm{p}$-JNK after MPP+ or MPP+/AS-IV treatments. Interestingly, compared with NC group, MPP+ upregulated $\mathrm{p}-\mathrm{JNK}$ protein level, indicating the response of p-JNK to MPP+ in astrocytes, co-treatment of AS-IV (10, 20 and $40 \mu \mathrm{M} / 1)$ downregulated MPP+-induced elevation of p-JNK. Thus, the data suggested that AS-IV might exert an anti-apoptotic effect via suppressing JNK apoptotic pathway.

Tumor-suppressor protein p53 was discovered to be activated following exposure to MPTP $(28,29)$. Furthermore, JNK signaling pathway collaborated with p53 in activating Bax and resulting in Bax-mediated cell apoptosis. Members of Bcl-2 family were reported to participate in the process of MPP+ generated cell death (30). Moreover, studies also indicated the importance of $\mathrm{Bax} / \mathrm{Bcl}-2$ ratio in determining cell fate (31). We conducted western blot to explore whether Bax and Bcl-2 were affected by $\mathrm{MPP}+$ in vitro. Results showed that, in MPP+ group, Bax protein level was significantly higher, while Bcl-2 protein level was significantly lower compared to NC group, both of which were reversed by AS-IV. Compared with NC group, obviously higher $\mathrm{Bax} / \mathrm{Bcl}-2$ ratio was found in MPP+ group which was in consistent with previous studies (32), and the elevated ratio was remarkably attenuated by AS-IV. These data indicated that the decline of $\mathrm{Bax} / \mathrm{Bcl}-2$ ratio by $\mathrm{AS}-\mathrm{IV}$ might due to repression of p-JNK protein level, an upstream regulator of $\mathrm{Bax} / \mathrm{Bcl}-2$.

In apoptotic cells, caspase- 3 could be activated by extrinsic (death ligand) and intrinsic (mitochondrial) pathways $(33,34)$. A recent study reported that in SH-SY5Y cells, AS-IV significantly reversed MPP+-induced elevated activity of caspase-3 (35). We carried out western blot to investigate the effects of AS-IV on caspase-3 in astrocytes. Results indicated that MPP+ elevated the immunoreactivity of cleaved caspase- 3 significantly. And astrocytes that were co-administrated with AS-IV $(20,40 \mu \mathrm{M} / 1)$ exhibited a significant lower caspase-3 activity than those treated with MPP+.

Taken together, we proposed that AS-IV might be a neuroprotective agent for $\mathrm{PD}$ via repressing the activation of $\mathrm{JNK} / \mathrm{Bax} / \mathrm{Bcl} 2 /$ caspase-3 signaling pathway.

\section{Acknowledgements}

We are appreciated for the kind help on experiments from Feng Xiao and Guanliang Cheng (Department of Neurology, Huai'an First People's Hospital, Nanjing Medical University).

\section{References}

1. Franco-Iborra S, Vila M and Perier C: The Parkinson disease mitochondrial hypothesis: Where are we at? Neuroscientist 22: 266-277, 2016.

2. Camilleri A and Vassallo N: The centrality of mitochondria in the pathogenesis and treatment of Parkinson's disease. CNS Neurosci Ther 20: 591-602, 2014.

3. Sanchez-Guajardo V, Tentillier N and Romero-Ramos M: The relation between $\alpha$-synuclein and microglia in Parkinson's disease: Recent developments. Neuroscience 302: 47-58, 2015.

4. Xie A, Gao J, Xu L and Meng D: Shared mechanisms of neurodegeneration in Alzheimer's disease and Parkinson's disease. Biomed Res Int 2014: 648780, 2014.

5. Takeuchi H, Mizuno T, Zhang G, Wang J, Kawanokuchi J, Kuno R and Suzumura A: Neuritic beading induced by activated microglia is an early feature of neuronal dysfunction toward neuronal death by inhibition of mitochondrial respiration and axonal transport. J Biol Chem 280: 10444-10454, 2005.

6. Luo Y, Qin Z, Hong Z, Zhang X, Ding D, Fu JH, Zhang WD and Chen J: Astragaloside IV protects against ischemic brain injury in a murine model of transient focal ischemia. Neurosci Lett 363 : 218-223, 2004.

7. Qiu YY, Zhu JX, Bian T, Gao F, Qian XF, Du Q, Yuan MY, Sun H, Shi LZ and Yu MH: Protective effects of astragaloside IV against ovalbumin-induced lung inflammation are regulated/mediated by T-bet/GATA-3. Pharmacology 94: 51-59, 2014.

8. Qiu L, Yin G, Cheng L, Fan Y, Xiao W, Yu G, Xing M, Jia R, Sun R, Ma X, et al: Astragaloside IV ameliorates acute pancreatitis in rats by inhibiting the activation of nuclear factor- $\kappa \mathrm{B}$. Int J Mol Med 35: 625-636, 2015.

9. Zhang WD, Zhang C, Liu RH, Li HL, Zhang JT, Mao C, Moran S and Chen CL: Preclinical pharmacokinetics and tissue distribution of a natural cardioprotective agent astragaloside IV in rats and dogs. Life Sci 79: 808-815, 2006.

10. Seifert G, Schilling K and Steinhauser C: Astrocyte dysfunction in neurological disorders: A molecular perspective. Nat Rev Neurosci 7: 194-206, 2006.

11. Kobayashi K, Hayashi M, Nakano H, Fukutani Y, Sasaki K, Shimazaki M and Koshino Y: Apoptosis of astrocytes with enhanced lysosomal activity and oligodendrocytes in white matter lesions in Alzheimer's disease. Neuropathol Appl Neurobiol 28: 238-251, 2002.

12. Szydlowska K, Zawadzka M and Kaminska B: Neuroprotectant FK506 inhibits glutamate-induced apoptosis of astrocytes in vitro and in vivo. J Neurochem 99: 965-975, 2006.

13. Lee J, Ziering A, Heineman SD and Berger L: Piperidine derivatives; 2-phenyl- and 2-phenylalkyl-piperidines. J Org Chem 12: 885-893, 1947. 
14. Pereira E A C, Aziz T Z: Parkinson's disease and primate research: past, present, and future. Postgraduate medical journal 82: 293-299, 2006.

15. Porras G, Li Q, Bezard E: Modeling Parkinson's disease in primates: the MPTP model. Cold Spring Harbor perspectives in medicine 2: a009308, 2012.

16. Seniuk NA, Tatton WG and Greenwood CE: Dose-dependent destruction of the coeruleus-cortical and nigral-striatal projections by MPTP. Brain Res 527: 7-20, 1990.

17. Hantraye P, Varastet M, Peschanski M, Riche D, Cesaro P, Willer JC and Maziere M: Stable parkinsonian syndrome and uneven loss of striatal dopamine fibres following chronic MPTP administration in baboons. Neuroscience 53: 169-178, 1993.

18. Przedborski S and Jackson-Lewis V: Mechanisms of MPTP toxicity. Mov Disord 13 (Suppl 1): S35-S38, 1998.

19. Dauer W and Przedborski S: Parkinson's disease: Mechanisms and models. Neuron 39: 889-909, 2003.

20. Ogawa N, Hirose Y, Ohara S, Ono T and Watanabe Y: A sireple quantitative hradykinesia test in MPIP treated mice. Res Commun Chem Pathol Pharmacol 50: 435-441, 1985.

21. Kubara H, Higuchi Y and Tadokoro S: Effects of central depressants on rota-rod and action performances in mice. Jpn J Pharmacol 27: 117-126, 1977.

22. Donnan GA, Willjs GL, Kaczmarczyk SJ and Rowe P: Motor function in the 1, methyl-4-phenyl-1,2,3,6-tetrahydropyridine treated mouse. J Neurol Sci 77: 185-191, 1987.

23. Davis RJ: Signal transduction by the JNK group of MAP kinases Cell 103: 239-252, 2000

24. Dickens M, Rogers JS, Cavanagh J, Raitano A, Xia Z, Halpern JR, Greenberg ME, Sawyers CL and Davis RJ: A cytoplasmic inhibitor of the JNK signal transduction pathway. Science 277: 693-696, 1997

25. Saporito MS, Thomas BA and Scott RW: MPTP activates c-Jun $\mathrm{NH}(2)$-terminal kinase (JNK) and its upstream regulatory kinase MKK4 in nigrostriatal neurons in vivo. J Neurochem 75 1200-1208, 2000.

26. Xia XG, Harding T, Weller M, Bieneman A, Uney JB and Schulz JB: Gene transfer of the JNK interacting protein-1 protects dopaminergic neurons in the MPTP model of Parkinson's disease. Proc Natl Acad Sci USA 98: 10433-10438, 2001.
27. Lotharius J, Falsig J, van Beek J, Payne S, Dringen R, Brundin P and Leist M: Progressive degeneration of human mesencephalic neuron-derived cells triggered by dopamine-dependent oxidative stress is dependent on the mixed-lineage kinase pathway. J Neurosci 25: 6329-6342, 2005.

28. Findley HW, Gu L, Yeager AM and Zhou M: Expression and regulation of $\mathrm{Bcl}-2, \mathrm{Bcl}-\mathrm{xl}$, and Bax correlate with p53 status and sensitivity to apoptosis in childhood acute lymphoblastic leukemia. Blood 89: 2986-2993, 1997.

29. Mandir AS, Przedborski S, JacksonLewis V, Wang ZQ, Simbulan-Rosenthal CM, Smulson ME, Hoffman BE, Guastella DB, Dawson VL and Dawson TM: Poly(ADP-ribose) polymerase activation mediates 1-methyl-4-phenyl-1,2,3,6-tetrahydropyridine (MPTP)-induced parkinsonism. Proc Natl Acad Sci USA 96: 5774-5779, 1999.

30. O'Malley KL, Liu J, Lotharius J and Holtz W: Targeted expression of BCL-2 attenuates MPP+ but not 6-OHDA induced cell death in dopaminergic neurons. Neurobiol Dis 14: 43-51, 2003.

31. Cory S and Adams JM: The Bcl2 family: Regulators of the cellular life-or-death switch. Nat Rev Cancer 2: 647-656, 2002.

32. Blum D, Torch S, Lambeng N, Nissou M, Benabid AL, Sadoul R and Verna JM: Molecular pathways involved in the neurotoxicity of 6-OHDA, dopamine and MPTP: Contribution to the apoptotic theory in Parkinson's disease. Prog Neurobiol 65: 135-172, 2001

33. Salvesen GS: Caspases: Opening the boxes and interpreting the arrows. Cell Death Differ 9: 3-5, 2002.

34. Ghavami S, Hashemi M, Ande SR, Yeganeh B, Xiao W, Eshraghi M, Bus CJ, Kadkhoda K, Wiechec E, Halayko AJ and Los M: Apoptosis and cancer: Mutations within caspase genes. J Med Genet 46: 497-510, 2009.

35. Zhang ZG, Wu L, Wang JL, Yang JD, Zhang J, Zhang J, Li LH, Xia Y, Yao LB, Qin HZ and Gao GD: Astragaloside IV prevents MPP+-induced SH-SY5Y cell death via the inhibition of Bax-mediated pathways and ROS production. Mol Cell Biochem 364: 209-216, 2012 